\title{
An Evaluation of the Relationship between Academic Performance And Physical Fitness Measures in California Schools
}

\author{
Sangeeta Singh and Shari McMahan \\ California State University Fullerton
}

\begin{abstract}
The purpose of this study was to evaluate the relationship between academic achievement and physical fitness in California schools. Data from the academic year 2004-2005 Fitnessgram were compared to reading, mathematics and science scores on the California Standards test (CST) of 253 elementary schools in the Orange County School District. Physical education teachers from the 10 lowest scoring and 10 highest scoring schools were interviewed regarding content of the physical education classes in their school. Simple correlation coefficients revealed a positive linear relationship between academic scores and physical fitness scores. The interview with the teachers revealed that most of the 10 lowest scoring schools did not have a designated physical education teacher. All of the 10 highest scoring schools had designated physical education teachers and followed the physical education guidelines recommended by the California Education Board.
\end{abstract}

(c) 2006 Californian Journal of Health Promotion. All rights reserved.

Keywords: academics, physical activity, obesity, children

\section{Introduction}

An understanding of the relation between health and academic performance of a student has significant implications. As good academic performance is directly related to university entrance and job opportunities, it has always been a matter of concern for both parents as well as students (Kim, Frongillo, Han, Oh, Kim, Jang, Won, Lee \& Kim, 2003). In days of evertightening budgets and ongoing criticism of the academic records of public schools, the tendency to cut funding for extra-curricular activities and physical education is stronger than ever which in-turn contributes to the overall problem of health, missed schools days, and school performance (Luepker, 1999). Student's health is on the decline and the current increase in the prevalence of childhood obesity has become one of the most important public health concerns in the United States today.

Childhood overweight and obesity has been compared to the threats of bio-terrorism and small pox and has been called the "fastest growing, most threatening disease in America”(Kaiser Permanente; obesity report,
2006). According to the Center for Disease Control (CDC), the percentage of overweight children aged 6-11 years has almost doubled since the early 1980's. The percentage of overweight adolescents has risen by nearly 300 percent.

Obesity rarely causes immediate, serious health consequences in childhood, however, it has been associated with many risk factors for cardiovascular diseases, hypertension, dislipidemia, and impaired glucose tolerance resulting in type 2 diabetes (Mikkila, LahtiKoski, Pietinen, Virtanen, \& Rimpela, 2003). More immediate consequences of obesity and overweight in children and adolescents are psychological and social. There are a number of studies which indicate that overweight and obese children are more likely to have low self-esteem and that they have higher rates of anxiety disorders, depression and other psychopathology (Zametkin, Zoon, Klein, \& Munson, 2004). In a population based study of 58 obese adolescents who were $40 \mathrm{~kg}$ overweight compared with closely matched controls, researchers found that obesity had a linear correlation with self- 
reported self-esteem. Obese children were not satisfied with their body and their physical abilities (Renman, Engstrom, Silfverdal, \& Aman, 1999).

To further investigate the relation between obesity and behavioral and socio-economic factors, Mikkila, Lahti-Koski, Pietinen, Virtanen, \& Rimpela (2003), conducted a crosssectional study in Finland, A total of 60,252 Finnish adolescents aged 14 to 16 years filled in a questionnaire about their health, health behaviors and socio-economic background. Results indicated that obesity was strongly associated with low socio-economic status of the family. Having economic problems in the family was also associated with a higher frequency of obesity. Good school performance was inversely associated with being obese in both boys and girls (Mikkila, Lahti-Koski, Pietinen, Virtanen, \& Rimpela, 2003). Obesity and overweight are not only associated with low self -esteem but also with intelligence test scores and school performance.

A cross-sectional study conducted on data from Danish draftees showed a clear inverse association between above the median BMI and intelligence test score and educational level. In particular, obese subjects with BMI> $31 \mathrm{~kg} / \mathrm{m}^{2}$ had significantly lower intelligence test scores compared to a non obese control group (Taras \& Potts-Datema, 2005).

Similar tendencies were also seen in a Chinese study in children who were tested with the Wechsler Intelligence Scale (IQ) for Children (revised) and the Eysenck Personality Questionnaire (EPQ). The tests were administered to 102 children with obesity and their controls in a case-control design. The mean age of the children was 9.8 years and they all attended primary school. It was found that children in the severe obesity category $(>50 \%$ overweight) had a significantly lower performance on IQ scores than the controls, and a significantly higher EPQ psychoticism score. These differences were not observed in children with milder degrees of obesity (Li, 1995).
Another study, conducted in Brazil, identified intellectual characteristics of 65 obese children aged 8-13 years compared to those of a control group from the same communities comprising 35 well-nourished, tall (>95th percentile for height) children who had normal weights for their height. It was concluded from the results that children with normal height/weight ratios had significant better performance in IQ than those in the obese group, had a wider range of interests, and better capacity for social adaptability (Campos, Singulem, Moraes, Escrivao \& Fisberg, 1996).

The results of another study in Thailand showed similar trends. Height/weight, GPA, and subject scores of 2252 primary school children were collected. GPA and subject scores were compared to current weight as well as to weight status recorded two years earlier. Study findings indicate that school performance (GPA) decreased with an increase in weight (Mosuwan, Lebel, Puetpaiboon, \& Junjana 1999).

Obese children showed poor academic performance than non obese counterparts not only because of low-self esteem and psychological stress but also because they missed school of other health conditions related with obesity and overweight. One hundred five children aged 5-18 referred by their physicians to a specialty clinic were studied with health related quality of life inventory. Number of days of school missed was part of the inventory. Control group data were taken from 800 healthy children from another study. The results indicated that obese children missed a median of 1 day in the preceding month, as compared to 0 days for healthy children. The mean number of days missed was 4.2 days for severely obese children and 0.7 days for healthy children (Schwimmer, Burwinkle, \& Varni, 2003).

Studies have also examined the relationship between increased physical activity, student's self esteem and academic achievement. A crosssectional study conducted in New Brunswick in sixth grade students concluded that physical activity levels were significantly related with self-esteem as well as with academic 
achievements in both mathematics and reading (Tremblay, Inman, \& Williams, 2000).

Another study conducted by Kim, Frongillo, Han, Oh, Kim, Jang, Won, Lee \& Kim (2003) provides evidence that physical status is related to school performance. The study was conducted in eight cities of South Korea among student's of 16 elementary, 14 middle schools and 14 high schools. Multiple linear regression analysis was used to investigate the association between academic performance, socio-economic status and physical activity. It was concluded that GPA was related to higher parental education. Physical fitness scores were also positively associated with academic performance.

Although obesity is known to have a genetic background, the rapid increase in prevalence suggests that the primary cause of this global phenomenon lies in lifestyle and environmental changes, such as decreased requirement for physical activity and greater abundance and availability of food (Flegal, 1999). Children today are less physically active than previous generations. People of previous generations walked long distances to school, now children are picked up by school buses in front of their houses; teenagers at driving age have cars. Children spend a maximum amount of time in front of the television or computer (Luepker, 1999).

Despite the evidence linking physical activity during childhood to immediate and later health and academic achievements, physical education programs in elementary and secondary schools have slowly eroded during the past few years (Shephard, 1997). Many educators and parents believe that spending time during school hours on physical activity inhibits children's chances of success in academic pursuits. Tightening budgets, reduced facilities and other lost resources have combined with an emphasis on academic subjects to reduce the amount of time devoted to physical education. The Department of Education also maintains that the time spent on physical activity should be better spent on academic pursuits (Tremblay, Inman, \& Williams, 2000).
The purpose of this study is to examine data on physical fitness and academic performance of elementary schools across Orange County and to evaluate the relationship between academic performance and physical activity. There is a growing body of research on the positive effects of physical activity on physical and psychological health, but the relationship between academic performance and physical activity has not been widely investigated. A study by Grissom (2005) evaluated the relation between physical fitness and academic performance in 5th, 7th, and 9th grade California public school students. No study has been conducted exclusively on Orange County elementary schools. This study will provide a comprehensive report on Orange County elementary schools physical fitness and academic performance data. The results of the study can provide an insight to school administration that physical activity has a positive effect on the overall school performance of a student and physical activity should be considered as part of a student's academic curriculum.

\section{Methods}

\section{Procedures and Measurements}

A total of 354 elementary schools were identified in the Orange County School District (OCSD) with published information on the school accountability report card for the academic year on the school website. Of 354 schools only 253 schools published the complete data required for the present study, that is; all California Standards test (CST) scores for reading, mathematics and science and physical fitness test scores (PFT) for the academic year 2004-2005 for the 5th grade. All CST and PFT scores were in percentages. Physical fitness test scores were measured utilizing the Fitnessgram which is the required physical fitness test to be administered to California students, since 1996. The Fitnessgram was developed by the Cooper Institute for Aerobics Research in Dallas, Texas. The Physical Fitness test measures five aspects: 1) aerobic capacity, 2) body composition, 3) trunk strength, 4) upper body strength, and 5) flexibility (California Law, 2003). 
The ten top scoring and 10 lowest scoring schools were identified and school representatives from these 20 schools were contacted and telephone interviews were conducted regarding physical education in the school using a structured questionnaire.

\section{Statistical Analysis}

The data analyses first calculated the mean scale scores for the CST in English-language arts, mathematics and science and PFT scores. Second, linear correlation methods were used to evaluate the correlation between English-arts, mathematics, science scores, and physical fitness test scores. Third, descriptive analysis was conducted on the interviews with the 20 physical education teachers.

\section{Results}

Descriptive statistics for all variables can be found in Table 1. To evaluate the relationship between Physical Fitness Test (PFT) and California Standard Test (CST), simple correlation coefficients were run for each grouptotal, male, female and economically disadvantaged (ED) CST and PFT scores. For each of the groups, CST scores were significantly correlated with the PFT scores. Total PFT scores were significantly correlated with English total scores, $\mathrm{r}=.598, \mathrm{p}<.001$; with total Math scores, $\mathrm{r}=.559, \mathrm{p}<.001$; with total science scores, $\mathrm{r}=.583, \mathrm{p}<.001, \mathrm{~N}=253$ (see Table 2).

Table 1

Descriptive Statistics for CST and PFT scores $(\mathrm{N}=253)$

\begin{tabular}{|l|c|c|}
\hline \multicolumn{1}{|c|}{ Variables } & M & SD \\
\hline CST Eng. Total & 46.54 & 22.14 \\
\hline CST Math Total & 53.02 & 19.63 \\
\hline CST Sci. Total & 33.14 & 22.89 \\
\hline CST Eng. Male & 44.00 & 21.43 \\
\hline CST Math Male & 54.18 & 19.45 \\
\hline CST Sci. Male & 36.67 & 23.98 \\
\hline CST Eng. Female & 50.58 & 22.24 \\
\hline CST Math Female & 53.05 & 19.47 \\
\hline CST Sci. Female & 31.07 & 22.47 \\
\hline CST Eng. ED & 33.71 & 15.58 \\
\hline CST Math ED & 42.09 & 15.32 \\
\hline CST Sci ED & 18.67 & 13.12 \\
\hline PFT Total & 31.75 & 16.46 \\
\hline PFT Male & 29.58 & 16.10 \\
\hline PFT Female & 34.12 & 19.00 \\
\hline
\end{tabular}

Table 2

Correlations for CST and PFT Scores of Total Students $(\mathrm{N}=253)$

\begin{tabular}{|l|l|l|l|l|}
\hline & CST Eng T & CST Math T & CST Sci T & PFT T \\
\hline CST Eng T & 1 & $.953^{* *}$ & $.898^{* *}$ & $.598^{* *}$ \\
\hline CST Math T & $.953^{* *}$ & 1 & $.859^{* *}$ & $.559^{* *}$ \\
\hline CST Sci T & $.898^{* *}$ & $.859^{* *}$ & 1 & $.583^{* *}$ \\
\hline PFT T & $.598^{* *}$ & $.559^{* *}$ & $.583^{* *}$ & 1 \\
\hline
\end{tabular}

** Correlation is significant at the 0.01 level (2-tailed) 
To further evaluate the relationship between CST scores and PFT scores based upon gender, simple correlation test were run between the CST and PFT scores on male students, and PFT scores were significantly correlated with English scores, $\mathrm{r}=.581, \mathrm{p}>.001$; with math scores, $\mathrm{r}=.540, \mathrm{p}<.001$; and with science scores, $\mathrm{r}=.578$, $\mathrm{p}<.001$. Correlation test were also used in identifying the relationship between female CST score and female PFT score, English score, $\mathrm{r}=.566, \mathrm{p}<.001$; math scores, $\mathrm{r}=.537, \mathrm{p}<.001$; and science scores, $\mathrm{r}=.548, \mathrm{p}<.001$ (see Table $3)$. To analyze how scores are related to PFT scores of economically disadvantaged students, correlation coefficients were run for their score (see Table 4) English score, $\mathrm{r}=.423, \mathrm{p}<.001$; math scores, $\mathrm{r}=.398, \mathrm{p}<.001$; and science scores, $\mathrm{r}=.361, \mathrm{p}<.001$.

Table 3

Correlation for CST and PFT Scores of Male and Female Students (N=253)

\begin{tabular}{|c|c|c|c|c|c|c|c|c|}
\hline & $\begin{array}{c}\text { CST } \\
\text { Eng M }\end{array}$ & $\begin{array}{c}\text { CST } \\
\text { Math M }\end{array}$ & $\begin{array}{c}\text { CST } \\
\text { Sci M }\end{array}$ & $\begin{array}{c}\text { PFT } \\
\text { M }\end{array}$ & $\begin{array}{c}\text { CST } \\
\text { Eng F }\end{array}$ & $\begin{array}{c}\text { CST } \\
\text { Math F }\end{array}$ & $\begin{array}{l}\text { CST } \\
\text { Sci F }\end{array}$ & $\begin{array}{c}\text { PFT } \\
\text { F }\end{array}$ \\
\hline CST Eng M & 1 & $.939 * *$ & $.894 * *$ & $.559 * *$ & $.971 * *$ & $.923 * *$ & $.842 * *$ & $.581^{* *}$ \\
\hline CST Math M & $.939 * *$ & 1 & $.856 * *$ & $.518 * *$ & $.923 * *$ & $.965 * *$ & $.816^{* *}$ & $.540 *$ \\
\hline CST Sci M & $.894 * *$ & $.856 * *$ & 1 & $.578 * *$ & $.873 * *$ & $.841 * *$ & $.917 * *$ & $.578 * *$ \\
\hline PFT M & $.559 * *$ & $.518 * *$ & $.532 * *$ & 1 & $.540 * *$ & $.509 * *$ & $.493 * *$ & $.814 * *$ \\
\hline CST Eng F & $.971 * *$ & $.923 * *$ & $.873 * *$ & $.540 * *$ & 1 & $.940 * *$ & $.839 * *$ & $.566 * *$ \\
\hline CST Math F & $.923 * *$ & $.965 * *$ & $.841 * *$ & $.509 * *$ & $.940 * *$ & 1 & $.823 * *$ & $.537 * *$ \\
\hline CST Sci F & $.842 * *$ & $.816 * *$ & $.917 * *$ & $.493 * *$ & $.839 * *$ & $.823 * *$ & 1 & $.548 * *$ \\
\hline PFT F & $.581 * *$ & $.540 * *$ & $.578^{* *}$ & $.814^{* *}$ & $.566 * *$ & $.537 * *$ & $.548 * *$ & 1 \\
\hline
\end{tabular}

Table 4

Correlations for CST and PFT Scores of ED Students ( $\mathrm{N}=253)$

\begin{tabular}{|l|l|l|l|l|}
\hline & CST Eng ED & CST Math ED & CST Sci ED & PFT T \\
\hline CST Eng ED & 1 & $.787^{* *}$ & $.501^{* *}$ & $.432^{* *}$ \\
\hline CST Math ED & $.787^{* *}$ & 1 & $.541^{* *}$ & $.398^{* *}$ \\
\hline CST Sci ED & $.501^{* *}$ & $.541^{* *}$ & 1 & $.361^{* *}$ \\
\hline PFT T & $.432^{* *}$ & $.398^{* *}$ & $.361^{* *}$ & 1 \\
\hline
\end{tabular}

** Correlation is significant at the 0.01 level (2-tailed)

The results indicate that CST scores of each group; total, male, female, and ED students were significantly correlated with their PFT scores, that is; as PFT scores increased CST scores also increased. There was a positive linear relationship between the CST scores of the students and their PFT scores.

The results of the telephone interview of the 10 lowest scoring schools in academics and PFT and the 10 highest scoring schools revealed that among the 10 lowest scoring schools; seven schools did not have a physical education (P. E.) teacher, two schools shared their P. E. teacher with two other schools so the students had P.E. classes once a week for 30 minutes. One school shared their P.E. teacher with five other schools so the students had irregular P.E. classes, sometimes once a week for 30 minutes, sometimes once in two weeks for 30 minutes. P.E. was integrated in math or science classes in the seven schools which did not have a P. E. teacher. In those schools, physical activity consisted of going in the playground and the 
students could choose what he/she wants to do, run, swing, or sit or students were engaged in some indoor activity. The teacher supervised that nobody got hurt.

The results of the 10 highest scoring schools revealed that eight schools had a designated P.E. teacher, two schools shared their P.E. teachers with one other school. The students had P.E. classes twice a week, 45 minutes each. The classes were very structured, each class started with some basic warm-up exercises and then students either played out in the field, for example, football/soccer or engaged in indoor exercises like yoga or aerobic exercises. Every two weeks new games were introduced to keep the students engaged and maintain the interest in physical activity. These schools also competed in inter-school sports competitions for elementary schools.

\section{Discussion}

This study examined the relationship between academic achievement and physical activity in Orange County, California elementary schools. It was hypothesized that students who scored high on the physical fitness test would score high on the academic achievement tests. The results support the hypothesis, there was a statistically significant positive linear relationship between physical fitness testing and academic achievement test results.

However, the results do not indicate causality. That is, it cannot be inferred from the data that improved physical fitness caused an increase or improvement in academic achievement or vice versa. It must be acknowledged however, that better general health and/or better living conditions were responsible for both higher fitness levels and higher levels of academic achievement. Previous research has demonstrated that as SES improves, so does overall health and it is also evident from this study, as the ten highest scoring schools both at fitness level and academic levels were located at comparatively high SES neighborhood.
The study was limited to elementary schools in Orange County, California. Only those schools which posted a complete School Accountability Report Card online for public review were evaluated. Secondary data was used in the study which was retrieved from school websites, so the accuracy of the data could not be endorsed. In addition, the study was not randomized; it included only elementary schools from the Orange County School District. The study did not take in account, the difference between schools, for example, school budget, number of teachers with full credentials, teacher's aids employed by the school. The study did not control for the factors which could affect a student's academic performance, such as parents' education and ethnicity.

It is clear that promoting physical activity in children will have a crucial role in life long prevention of many health disorders. U.S. data on activity levels of children, particularly pertaining to whether children are currently meeting recommendations for physical activity, are scarce. A study of a nationally representative sample of 4063 children aged 8-16 years showed that $20 \%$ of US children do not get vigorous exercise more than twice per week. Moreover, $67 \%$ of children watch $>2$ hours television per day. Research has demonstrated that physical education does not reduce academic performance, but studies have linked physical activity with improved academic performance. Schools can play a vital role in promoting physical activity and life long behavior change. Schools are the only institutions which have structured and continuous contact with nearly all children. Most schools have all the facilities and equipment and staff to provide instructions and supervision. Schools have the ability to reach out to low income children who may not have other opportunities for physical activity. School based physical education may be the only training some children ever have toward living a healthy lifestyle (Goran, Reynolds, \& Lindquist, 1999). Thus, subjects such as math, English, science, and physical education should be part of every academic core curriculum. 


\section{References}

California Law. (2003). Education Code, Section 60800. Retrieved June 1, 2006, from http://www.leginfo.ca.gov/calaw.html

Campos, A. L., Sigulem, D., Moraes, D. E., Escrivao, A. M., Fisberg, M. (1996). Intelligent quotient of obese children and adolescents by the Weschler scale. Review of Saude Publica, 30, 85-90.

Flegal, K. M. (1999). The obesity epidemic in children and adults: current evidence and research issues. Medicine \& Science in Sports \& Exercise, 31, 509-514.

Goran, M. I., Reynolds, K. D., \& Lindquist, C. H. (19999). Role of physical activity in the prevention of obesity in children. International Journal of Obesity, 23, S18-S33.

Grissom, J. B. (2005). Physical fitness and academic achievement. Journal of Exercise Physiology, 8, 1125.

Kaiser Permanente. (2006). Childhood obesity report. New York Times.

Kim, H. Y. P., Frongillo, E. A., Han, S. S., Oh, S. Y., Kim, W. K., Jang, Y. A., Won, H. S., Lee, H. S., \& Kim, S. H. (2003). Academic performance of Korean children is associated with dietary behaviours and physical status. Asian Journal of Clinical Nutrition, 12, 186-192.

Li, X. (1995). A study of intelligence and personality in children with simple obesity. International Journal of Obesity Related Metabolic Disorders, 19, 355-357.

Luepker, R. V. (1999). How physical active are American children and what can we do about it? International Journal of Obesity, 23, S12-S17.

Mikkila, V., Lahti-Koski, M., Pietinen, P., Virtanen, S. M., \& Rimpela, M. (2003). Association of obesity and weight dissatisfaction among Finnish adolescents. Public Health Nutrition, 6, 49-56.

Mo-suwan, L., Lebel, L., Puetpaiboon, A., \& Junjana, C. (1999). School performance and weight status of children and young adolescents in a transitional society in Thailand. International Journal of Obesity, 1999, 272-277.

Renman, C., Engstrom, I., Silfverdal, S. A., \& Aman, J. (1999). Mental health and psychosocial characteristics in adolescent obesity: A population-based case-control study. Acta Paediatr, 88, 998-1003.

Schwimmer, J. B., Burwinkle, T. M., \& Varni, J. W. (2003). Health-related quality of life of severely obese children and adolescents. Journal of American Medical Association, 289, 1813-1819.

Shepard, R.J. (1997). Curricular physical activity and academic performance. Pediatric Exercise Science, 9, 113-126.

Taras, H., \& Potts-Datema, W. (2005). Obesity and student performance at school. Journal of School Health, 75, 291-295.

Tremblay, M. S., Inman, J. W., \& Williams, J. D. (2000). The relationship between physical activity, selfesteem, and academic achievement in 12-year-old children. Pediatric Exercise Science, 12, 312323.

Zametkin, A. J., Zoon, C. K., Klein, H. W., \& Munson, S. (2004). Psychiatric aspects of child and adolescent obesity: A review of past 10 years. Journal of the American Academy of Child and Adolescent Psychiatry, 43, 134-150.

\section{Acknowledgements}

This journal article/publication was supported by grant/cooperative agreement number 1 RO1 DP00020901 from the CDC. Its contents are solely the responsibility of the authors and do not necessarily represent the official views of the CDC. 
Author Information

Sangeeta Singh, MPH

Research Assistant

Department of Health Science

California State University Fullerton

PO Box 6870

Fullerton, CA 92834-6870

Shari McMahan, Ph.D.

Professor and Chair

Department of Health Science

California State University Fullerton

PO Box 6870

Fullerton, CA 92834-6870 